\title{
Preparation of Zinc Oxide and Zinc Sulfide Powders by Controlled Precipitation from Aqueous Solution
}

\author{
Tito Trindade, ${ }^{a}$ Júlio D. Pedrosa de Jesus ${ }^{\star a}$ and Paul O'Brien ${ }^{b}$ \\ ${ }^{a}$ Department of Chemistry, University of Aveiro, 3800 Aveiro, Portugal \\ ${ }^{b}$ Department of Chemistry, Queen Mary and Westfield College, Mile End Road, London, UK E1 4NS
}

\begin{abstract}
$\mathrm{ZnO}$ and $\mathrm{ZnS}$ powders were prepared from aqueous solutions of zinc salts in the presence of ethylenediamine or triethanolamine. The morphology of the powders was analysed by scanning electron microscopy and infrared spectroscopy. The effect of the experimental conditions upon the size and shape of the particles is described with a special emphasis on the role of the organic ligand.
\end{abstract}

There is considerable current interest in developing microcrystalline powders suitable for use as precursors for ceramic materials. This work forms part of various efforts to produce high-performance ceramics of homogeneous composition and microstructure, as such materials should have improved reliability as compared to conventional materials. ${ }^{1}$ The electrical properties of zinc oxide are also markedly affected by the characteristics of the precursors used to prepare an individual sample, these properties are crucial in defining the suitability of zinc oxide for use in varistors. ${ }^{2-5}$ Zinc sulfide is another example of a material for which the control of particle formation may be of importance as this material is used in luminescence devices and pigments. ${ }^{6}$

Chemical methods have been applied to the synthesis of powdered materials, and submicrometre particles of narrow size distribution, high purity and uniform morphology have been achieved. ${ }^{1,7,8}$ Although technological interest in such controlled synthesis is recent, many natural systems synthesize biominerals with remarkable properties. ${ }^{9}$

Matijevic ${ }^{8}$ showed that well defined hydrated metal oxide particles, as well as other inorganic solids, can be precipitated from homogeneous aqueous solution by several methods including the thermal treatment of solutions of coordination complexes. The method is based on forming a complex sufficiently stable to prevent spontaneous precipitation at room temperature, i.e. masking the metal ion with a suitable ligand. Raising the temperature promotes the dissociation of the complex and allows the controlled generation of free metal

Table 1 Experimental conditions for the preparation of $\mathrm{ZnO}$ samples using zinc nitrate at $\mathrm{pH} 13.0$

\begin{tabular}{cccc}
\hline sample & aging temp. $/{ }^{\circ} \mathrm{C}$ & aging time/min & organic ligand \\
\hline A & 150 & 120 & en \\
B & 150 & 120 & tea \\
C & 100 & 120 & en \\
D & 100 & 120 & tea \\
E & 100 & 120 & - \\
\hline
\end{tabular}

ion which, on hydrolysis, leads to precipitation. Well defined particles of iron oxides, ${ }^{10}$ nickel and cobalt both as metal or oxide ${ }^{11}$ have been prepared by such methods. If an appropriate chalcogenide source is added, such methods can be used to prepare sulfides and selenides. ${ }^{8}$ Needle-like crystals of $\mathrm{ZnO}$ were obtained by the hydrothermal decomposition of aqueous solutions of $\mathrm{Na}_{2} \mathrm{Zn}-\mathrm{EDTA}^{12}$ and spherical particles of $\mathrm{ZnO}$ were prepared using a spray pyrolysis method. ${ }^{13}$ The controlled preparation of $\mathrm{ZnS}$ particles has been achieved ${ }^{14}$ using thioacetamide as a source of sulfide, but with no other added organic ligand.

This paper reports the synthesis and characterization of $\mathrm{ZnO}$ and $\mathrm{ZnS}$ powders by precipitation from homogeneous solution, and the effect of experimental conditions on the morphology of the products is discussed. The work is part of a programme aimed at collecting systematic information about the role of chelating agents in the control of powder morphologies which should help to underpin the mechanism initially proposed by LaMer and Dinegar ${ }^{15}$ for the formation and shape control of colloidal particles.

\section{Experimental}

\section{Chemicals}

The following chemicals were used without further purification: zinc nitrate hexahydrate, $\mathrm{Zn}\left(\mathrm{NO}_{3}\right)_{2} \cdot 6 \mathrm{H}_{2} \mathrm{O}$ (Merck); zinc sulfate heptahydrate, $\mathrm{ZnSO}_{4} \cdot 7 \mathrm{H}_{2} \mathrm{O}$ (Merck); zinc chloride, $\mathrm{ZnCl}_{2}$ (Merck); zinc acetate dihydrate, $\mathrm{Zn}$ $\left(\mathrm{CH}_{3} \mathrm{CO}_{2}\right)_{2} \cdot 2 \mathrm{H}_{2} \mathrm{O}$ (Merck); sodium hydroxide, NaOH pellets (Pronalab); nitric acid $65 \%, \mathrm{HNO}_{3}$ (Merck); sodium chloride, $\mathrm{NaCl}$ (Merck); sodium nitrate, $\mathrm{NaNO}_{3}$ (Merck); sodium sulfate decahydrate, $\mathrm{Na}_{2} \mathrm{SO}_{4} \cdot 10 \mathrm{H}_{2} \mathrm{O}$ (Merck); sodium acetate, $\mathrm{NaCH}_{3} \mathrm{CO}_{2}$ (Merck); ammonia, $\mathrm{NH}_{3}$ (Merck); ethanolamine, $\mathrm{NH}_{2} \mathrm{CH}_{2} \mathrm{CH}_{2} \mathrm{OH}$, (Merck); triethanolamine (tea), $\mathrm{N}\left(\mathrm{CH}_{2} \mathrm{CH}_{2} \mathrm{OH}\right)_{3}$ (Merck); diethylamine, $\mathrm{NH}\left(\mathrm{CH}_{2} \mathrm{CH}_{3}\right)_{2}$ (Merck); ethylenediamine (en), $\mathrm{NH}_{2} \mathrm{CH}_{2} \mathrm{CH}_{2} \mathrm{NH}_{2}$ (Merck); diethylenetriamine (dien), $\mathrm{NH}\left(\mathrm{CH}_{2} \mathrm{CH}_{2} \mathrm{NH}_{2}\right)_{2}(\mathrm{BDH})$; triethylenetetramine (trien), $\mathrm{NH}_{2} \mathrm{CH}_{2} \mathrm{CH}_{2} \mathrm{NHCH}_{2} \mathrm{CH}_{2} \mathrm{NH}-$

Table 2 Experimental parameters used in the prepartion of $\mathrm{ZnO}$ powders

\begin{tabular}{cccccc}
\hline ligand & $\mathrm{pH}\left(20^{\circ} \mathrm{C}\right)$ & anion $^{a}$ & time $/ \mathrm{min}$ & $T /{ }^{\circ} \mathrm{C}$ & $I\left(\mathrm{NaNO}_{3}\right) / \mathrm{mol} \mathrm{kg}^{-1}$ \\
\hline tea & 10.0 & $\mathrm{NO}_{3}^{-}$ & 5 & 70 & 0.31 \\
en & 11.0 & $\mathrm{SO}_{4}{ }^{-2}$ & 30 & 80 & 0.56 \\
- & 12.0 & $\mathrm{Cl}^{-}$ & 60 & 90 & 0.81 \\
- & 13.0 & $\mathrm{CH}_{3} \mathrm{CO}_{2}{ }^{-}$ & 120 & 100 & 1.06 \\
- & - & - & 240 & $150^{b}$ & not controlled \\
\hline
\end{tabular}

${ }^{a}$ The respective zinc salt was used and an excess of the sodium salt $(0.025$ or $0.05 \mathrm{~mol})$ was added to $50 \mathrm{~cm}^{3}$ of solution. ${ }^{b}$ Hydrothermal conditions. 
Table 3 Results from precipitation experiments of aqueous solutions of zinc nitrate and organic ligands at room temperature and $\mathrm{pH} 12.0$

\begin{tabular}{cc}
\hline ligand $^{a}$ & solid \\
\hline ammonia & zinc hydroxide \\
diethylamine & zinc hydroxide \\
zinc hydroxide \\
monoethanolamine & none \\
triethanolamine & none \\
ethylenediamine & none \\
diethylenetriamine & none \\
triethylenetetramine & none \\
nitrilotriacetic acid & none \\
EDTA &
\end{tabular}

${ }^{a}\left[\mathrm{Zn}^{2+}\right]=0.02 \mathrm{~mol} \mathrm{dm}{ }^{-3} ;[$ ligand $]:\left[\mathrm{Zn}^{2+}\right]=5: 1$.

Table 4 Results from precipitation experiments of aqueous solutions of zinc nitrate and organic ligands at 100 and $150^{\circ} \mathrm{C}$, aging time $2 \mathrm{~h}$ and $\mathrm{pH} 12.0$

\begin{tabular}{cc}
\hline ligand $^{a}$ & solid \\
\hline triethanolamine & $\mathrm{ZnO}$ \\
ethylenediamine & $\mathrm{ZnO}$ \\
diethylenetriamine & none \\
triethylenetetramine & none \\
nitrilotriacetic acid & none \\
EDTA & none \\
\hline
\end{tabular}

${ }^{a}\left[\mathrm{Zn}^{2+}\right]=0.02 \mathrm{~mol} \mathrm{dm}{ }^{-3} ;[$ ligand $]:\left[\mathrm{Zn}^{2+}\right]=5: 1$.

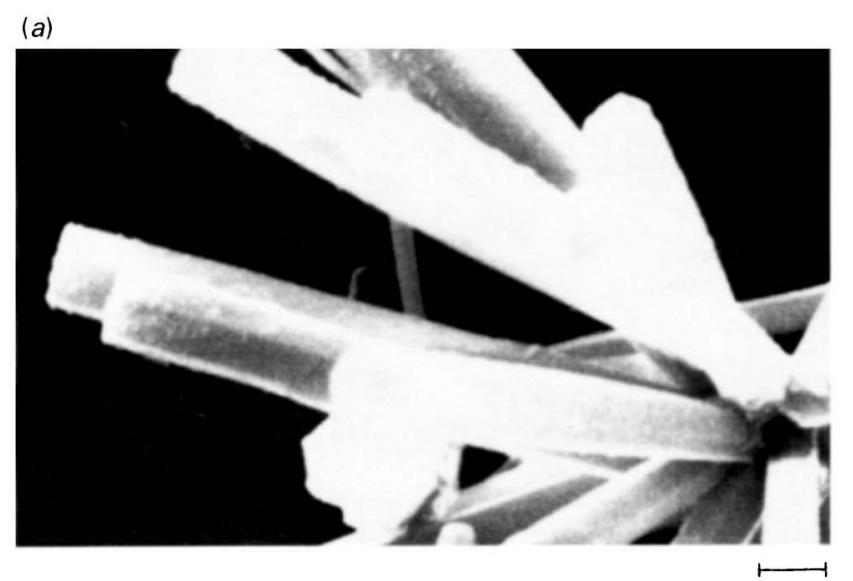

$1.0 \mu \mathrm{m}$

(b)

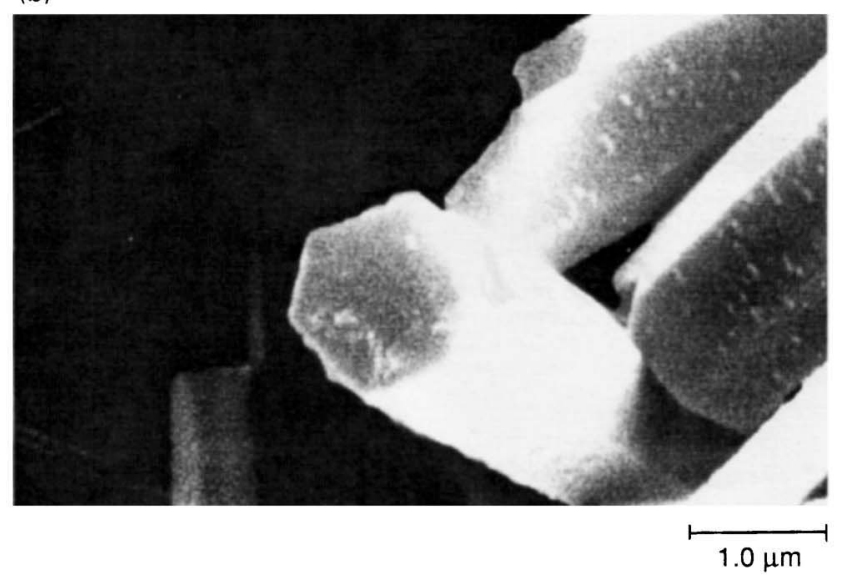

Fig. 1 SEM images of $\mathrm{ZnO}$ obtained by the hydrothermal treatment $\left(150^{\circ} \mathrm{C}\right)$ in the presence of: $(a)$ ethylenediamine; $(b)$ triethanolamine (a)

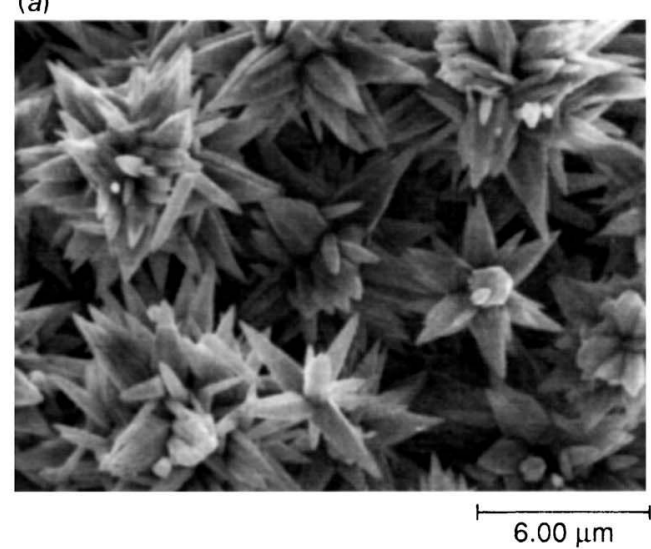

(b)

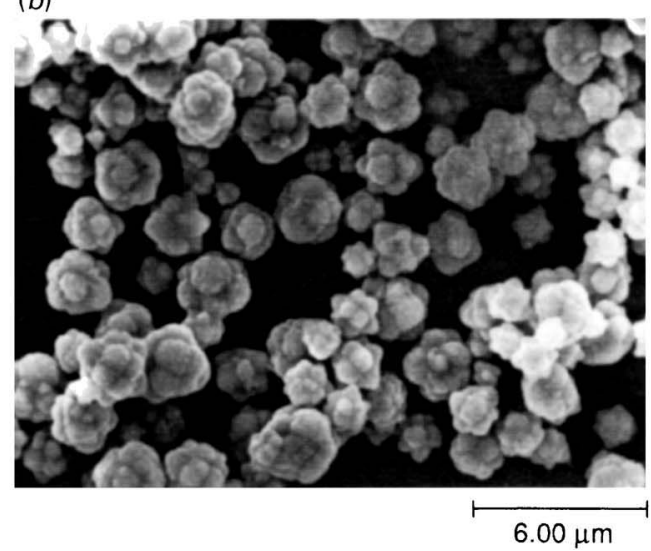

Fig. 2 SEM images of $\mathrm{ZnO}$ obtained at $100^{\circ} \mathrm{C}$ in the presence of (a) ethylenediamine; (b) triethanolamine

$\mathrm{CH}_{2} \mathrm{CH}_{2}$ (Riedel-de-Haën); EDTA, $\left(\mathrm{HO}_{2} \mathrm{CCH}_{2}\right)_{2}-$ $\mathrm{NCH}_{2} \mathrm{CH}_{2} \mathrm{~N}\left(\mathrm{CH}_{2} \mathrm{CO}_{2} \mathrm{H}\right)_{2}$ (Carlo Erba); nitrilotriacetic acid trisodium salt, $\mathrm{N}\left(\mathrm{CH}_{2} \mathrm{COONa}\right)_{3}$ (ICN); 2-mercaptoethanol, $\mathrm{HSCH}_{2} \mathrm{CH}_{2} \mathrm{OH}$ (Merck); o-phthaldialdehyde. $\mathrm{C}_{6} \mathrm{H}_{4}(\mathrm{CHO})_{2}$ (BDH); thioacetamide, $\mathrm{CH}_{3} \mathrm{CSNH}_{2}$ (Merck).

Sodium hydroxide solutions were prepared ( 1 and $4 \mathrm{~mol}$ $\mathrm{dm}^{-3}$ ) using boiled deionized water. Nitric acid solutions of the same molarity were prepared by dilution of the concentrated acid. Stock aqueous solutions of zinc $\left(0.04 \mathrm{~mol} \mathrm{dm}^{-3}\right)$ and ligand $\left(0.2 \mathrm{~mol} \mathrm{dm}^{-3}\right)$ were prepared. All the solutions were filtered using $0.45 \mu \mathrm{m}$ Millipore membranes before use.

Determination of en was performed by the colorimetric method described by Hihara et al. ${ }^{16}$ using a Varian DMS 300 spectrometer. The stock solutions were diluted 1000 -fold for the determination.

\section{Particle Preparation}

In a typical screening procedure equal volumes of ligand and $\mathrm{Zn}^{\mathrm{II}}$ stock solutions were mixed and the $\mathrm{pH}$ adjusted to 12.0 . The final mixture was left to stand with stirring, at room temperature, for at least 1 day. Thermal treatment of the solutions was performed only for those which did not give a spontaneous precipitate at room temperature. Heating procedures included refluxing (e.g. for $2 \mathrm{~h}$ ) or heating the solutions in PTFE reaction bombs, in an oven (e.g. $2 \mathrm{~h}$ at $\left.150^{\circ} \mathrm{C}\right)$.

Another procedure involved the addition of sodium hydroxide $\left(4 \mathrm{~mol} \mathrm{dm} \mathrm{dm}^{-3}\right)$ to a solution of the zinc salt $(0.02 \mathrm{~mol}$ $\mathrm{dm}^{-3}$ ). Initially a precipitate formed which dissolved at $\mathrm{pH}>13.5$. This solution was filtered and then refluxed; a precipitate then formed. The precipitates formed by both procedures were removed by filtration with $0.45 \mu \mathrm{m}$ Millipore 

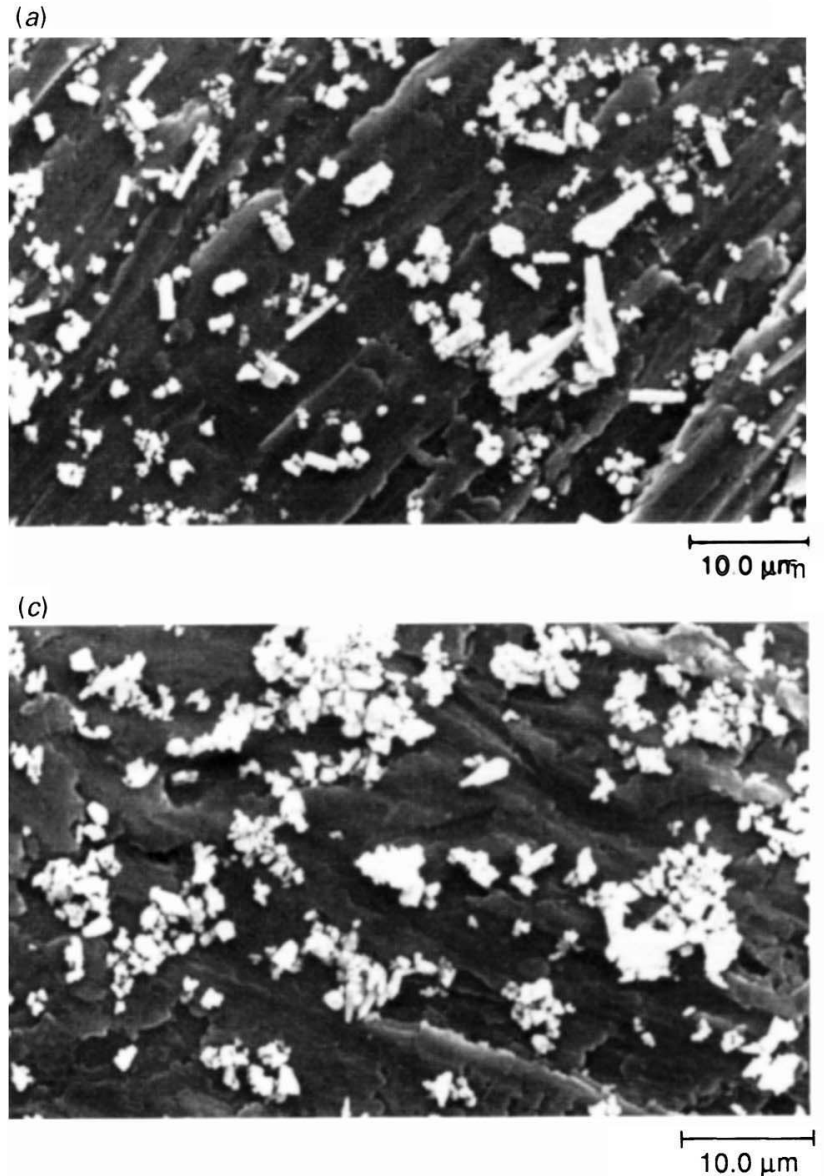

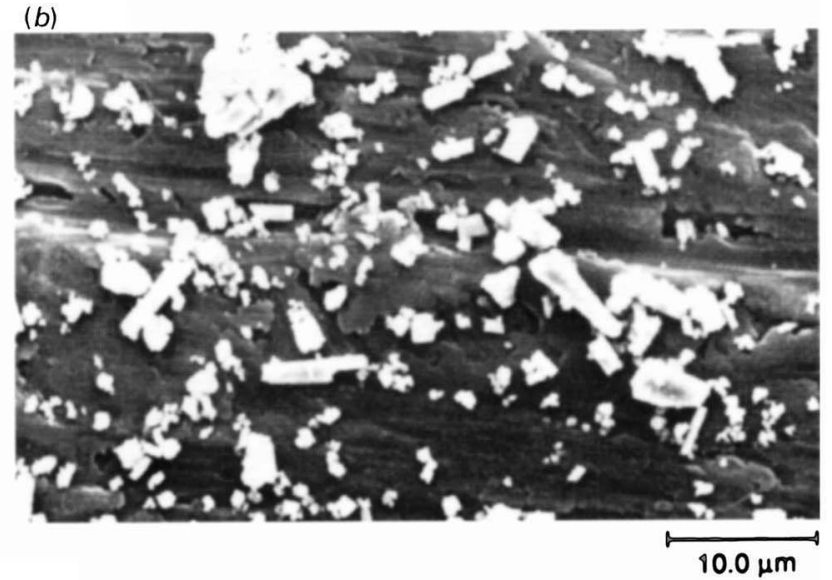

(d)

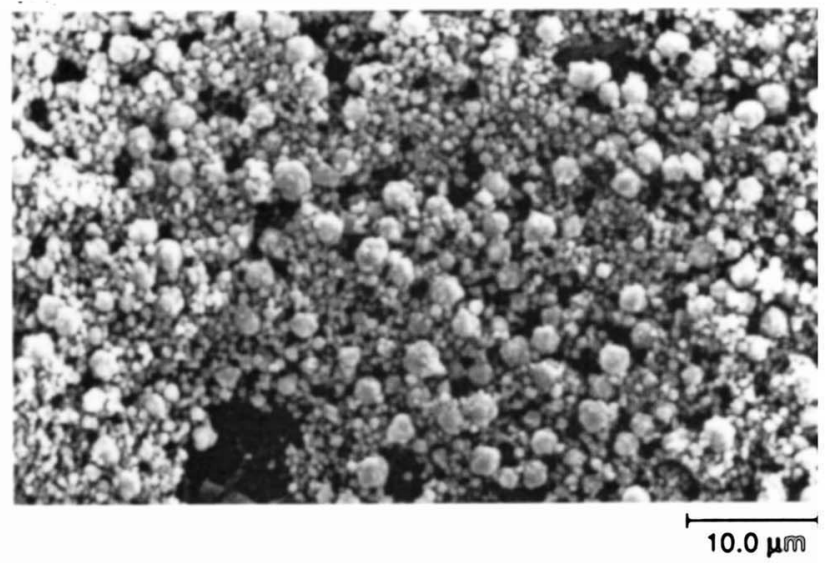

Fig. 3 SEM images of $\mathrm{ZnO}$ after the milling of the powders: $(a)$ sample A; $(b)$ sample B; $(c)$ sample C; and $(d)$ sample D

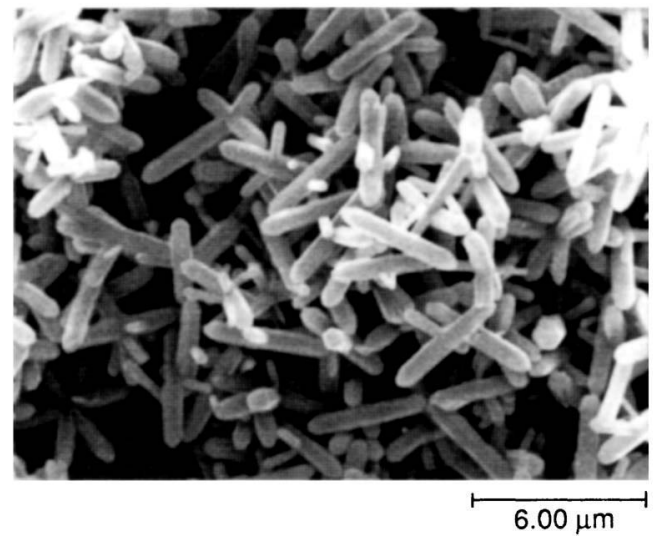

Fig. 4 SEM image of $\mathrm{ZnO}$ obtained at $100^{\circ} \mathrm{C}$ in the absence of organic ligand

membranes, washed with deionized water and dried in a desiccator over silica gel at room temperature.

The various powders obtained were analysed (see Table 1 for sample identification). The effect of other experimental parameters associated with the preparation of the $\mathrm{ZnO}$ powders was studied by systematically varying the reaction conditions (see Table 2).

$\mathrm{ZnS}$ powders were prepared using procedures similar to those used in the preparation of $\mathrm{ZnO}$. Thioacetamide was used to generate the sulfide ions.

\section{Particle Characterization}

The X-ray analysis of the powders was performed using a Philips PW 1729 generator using nickel-filtered $\mathrm{Cu} \cdot \mathrm{K} \alpha$ radiation. JEOL JSM-35C and Hitachi S-4100 scanning electron microscopes were used. The materials were prepared for microscopy by resuspension in water followed by ultrasonication. Aliquots of the suspensions were then kept on high-purity aluminium rods at room temperature in a desiccator over calcium chloride until the liquid had evaporated. The infrared spectra were recorded with a Mattson Polaris FTIR spectrometer using pellets of $1 \mathrm{mg}$ of the sample and $150 \mathrm{mg}$ of spectroscopic-grade $\mathrm{KBr}$.

\section{Results and Discussion}

Preparation of $\mathrm{ZnO}$ and $\mathrm{ZnS}$ Powders

Preliminary studies of the thermal and hydrothermal treatment of aqueous solutions of zinc in the presence of a wide variety of ligands have been reported. ${ }^{17}$ The results of these studies suggest that en and tea are the most promising metalion buffers for a detailed study.

Using similar systems but with different experimental conditions Matijevic and co-workers have obtained ${ }^{13,19} \mathrm{ZnO}$ particles with morphological characteristics similar to those described in our preliminary report. ${ }^{17}$ However, in the present paper the influence of a wider range of experimental conditions on the powder characteristics are reported.

The addition of an organic ligand to a solution of a zinc salt may prevent or inhibit the precipitation of zinc hydroxide. 
(a)

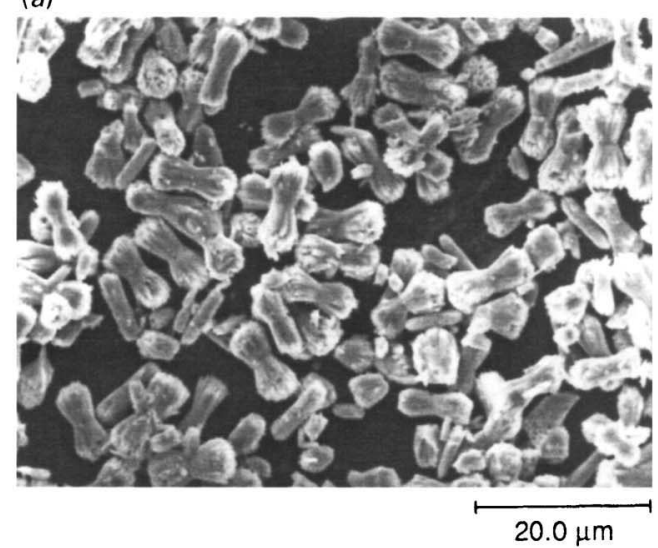

(b)

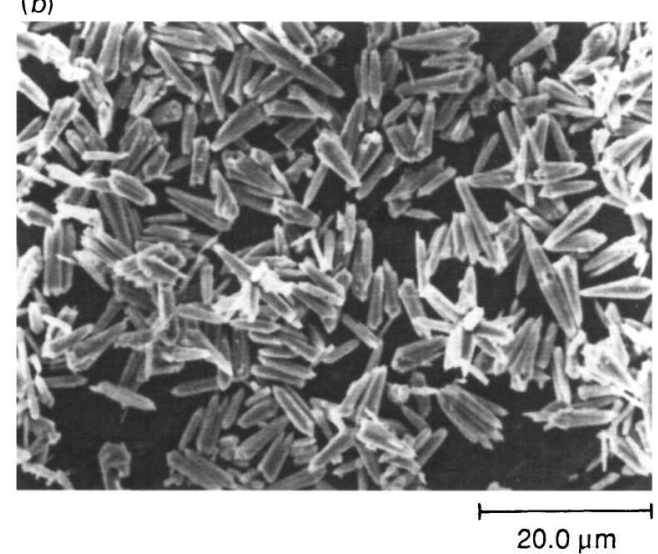

Fig. 5 SEM images of $\mathrm{ZnO}$ prepared $(a)$ in the presence of an excess of sulfate ions and ethylenediamine and (b) from a solution with an ionic strength of $1.06 \mathrm{~mol} \mathrm{~kg} \mathrm{~g}^{-1}$ and in the presence of ethylenediamine

In order to select ligands which prevent the spontaneous, immediate formation of solid, precipitate-screening experiments were carried out as described in the Experimental section. The results of these studies (all carried out at room temperature) are summarized in Table 3 for a [ligand]: $\left[\mathrm{Zn}^{2+}\right]$ ratio of $5: 1$. The presence of the amines, aminopolycarboxylic acids and tea prevents the precipitation of the solid at room temperature and these ligands were chosen for more detailed investigation.

The white precipitates obtained from the solutions at room temperature exhibit very poorly defined X-ray diffraction patterns with no well defined peaks, the material formed being $\mathrm{X}$-ray amorphous. The composition of the samples was confirmed as hydrated zinc oxide by comparing their infrared spectra with that of the precipitate obtained by mixing solutions of sodium hydroxide and zinc nitrate.

Zinc oxide was observed to precipitate after solutions containing tea or en were heated at pH 12.0-13.0. Hydrated zinc hydroxide precipitate is unstable at temperatures $>35^{\circ} \mathrm{C}$ with respect to $\mathrm{ZnO}$, in alkaline solution ${ }^{20}$ and at high $\mathrm{pH}$ the formation of the oxide is expected. Ligands other than ethylenediamine or triethanolamine totally inhibited precipitation under the conditions studied, even using higher aging temperatures, see Table 4.

There appears to be only one report in the literature ${ }^{14}$ of the preparation of $\mathrm{ZnS}$ particles of uniform morphology by the thermal decomposition of solutions of thioacetamide and zinc. The procedure reported involved a two-step process. No added organic ligand was used, other than the thioacetamide used as the source of sulfide ion. This method ${ }^{14}$ involved the preparation of $\mathrm{ZnS}$ seeds from a solution of zinc nitrate, nitric
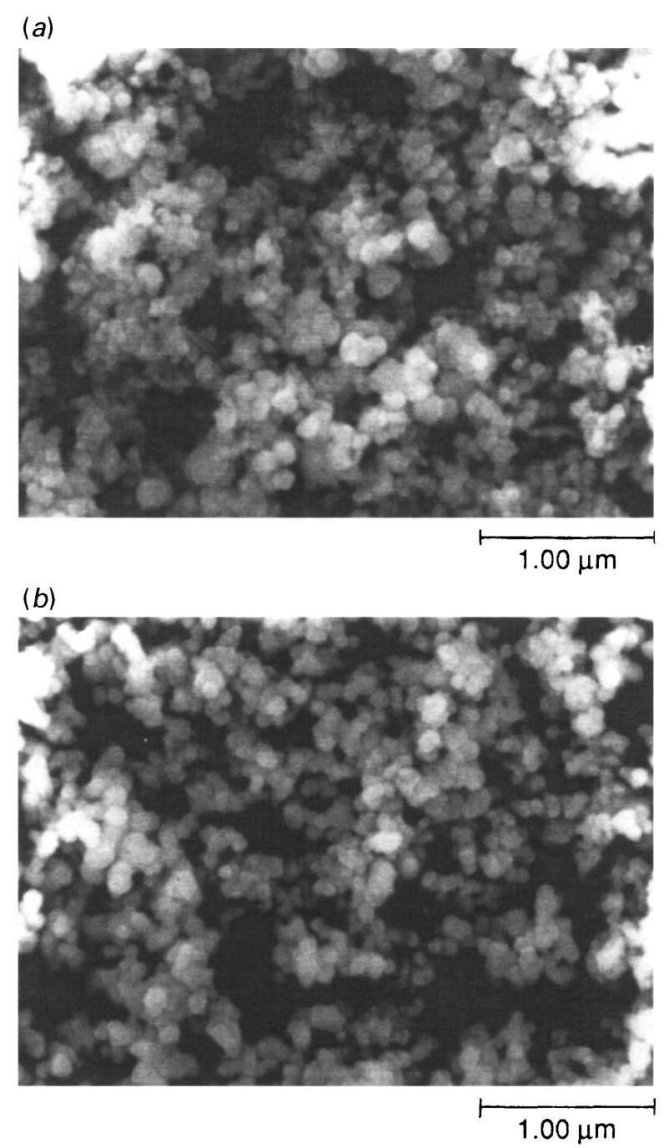

Fig. 6 SEM images of $\mathrm{ZnS}$ prepared at $60 \mathrm{C}$ for $2 \mathrm{~h}$ from solutions containing thioacetamide and (a) ethylenediamine or (b) triethanolamine

acid and thioacetamide, which were allowed to age further at an elevated temperature. The fact that the ligands en and tea had a marked effect on the morphology of the particles led us to investigate the effect of these chelating agents on the preparation of $\mathrm{ZnS}$.

When alkaline or acidic solutions of thioacetamide were heated in the presence of metal ions, metal sulfides precipitated. In a formal sense the reaction is a consequence of the hydrolysis of thioacetamide, which may be represented as:

$$
\mathrm{CH}_{3} \mathrm{CSNH}_{2}+2 \mathrm{H}_{2} \mathrm{O} \rightarrow \mathrm{CH}_{3} \mathrm{CO}_{2} \mathrm{NH}_{4}+\mathrm{H}_{2} \mathrm{~S}
$$

In an initial attempt to prepare $\mathrm{ZnS}$ particles, alkaline solutions containing the organic ligands en or tea, zinc nitrate and thioacetamide were heated at 60 or $100{ }^{\circ} \mathrm{C}$. However, only for acidic conditions was the preparation of well defined $\mathrm{ZnS}$ particles successful.

\section{Influence of Preparation Methods on Powder Characteristics}

The powders obtained by thermal treatment were identified as being zinc oxide (wurtzite, hexagonal) or zinc sulfide (sphalerite, cubic). The materials were identified by comparing their diffraction patterns with published data. ${ }^{21}$ The peaks for the zinc oxide samples were well defined, indicating that the samples were of good microcrystallinity. The best patterns were obtained for the powders prepared in closed vessels at the higher temperatures (samples A and B, Table 1). The ZnS particles were all of ill defined crystallinity, although the characteristic reflections of the cubic form could be observed.

The morphology of the particles was analysed by scanning electron microscopy (SEM). The $\mathrm{ZnO}$ particles obtained at 
$150^{\circ} \mathrm{C}$ were present as twinned crystals in which the hexagonal crystal habit of the wurtzite type structure is evident (Fig. 1). These particles are similar to those obtained by other authors using hydrothermal methods. ${ }^{12,18}$ When the reflux treatment was applied to the reaction mixtures a different morphology was observed with smaller polycrystalline particles. The effect of the ligand on the particle morphology is remarkable (Fig. 2): $\mathrm{ZnO}$ particles obtained in the presence of tea are nodular aggregates, but when en is used the particles are acicular. Preferential growth in the $c$ direction has possibly occurred from a particle centre where twinning took place. When the powder samples obtained in the presence of en either from reactions at $150^{\circ} \mathrm{C}$, or from the reflux method, were mechanically milled the particles break from several sites [Fig. $3(a)-(c)]$. The same milling procedure applied to samples prepared in the presence of tea by the reflux methods deaggregates the material into smaller nodular particles, some of them being broken while others remain intact [Fig. 3(d)].

In the absence of organic ligands, spontaneous precipitation may occur in alkaline solutions at room temperature. Zinc hydroxide is slightly soluble in water and becomes more soluble as the $\mathrm{pH}$ is increased (or lowered) above certain values. The dissolution of the precipitate is possible in a strongly alkaline medium with the formation of hydroxycomplexes such as $\left[\mathrm{Zn}(\mathrm{OH})_{3}\right]^{-}$and $\left[\mathrm{Zn}(\mathrm{OH})_{4}\right]^{2-}$ in solution. ${ }^{22}$ When a clear zinc solution was refluxed at $\mathrm{pH} 13.5$, a powder formed (sample E), which was identified by X-ray diffraction as $\mathrm{ZnO}$. SEM of this powder (Fig. 4) reveals prismatic particles of a shape and size distinctly different from those obtained in the presence of the organic ligands.
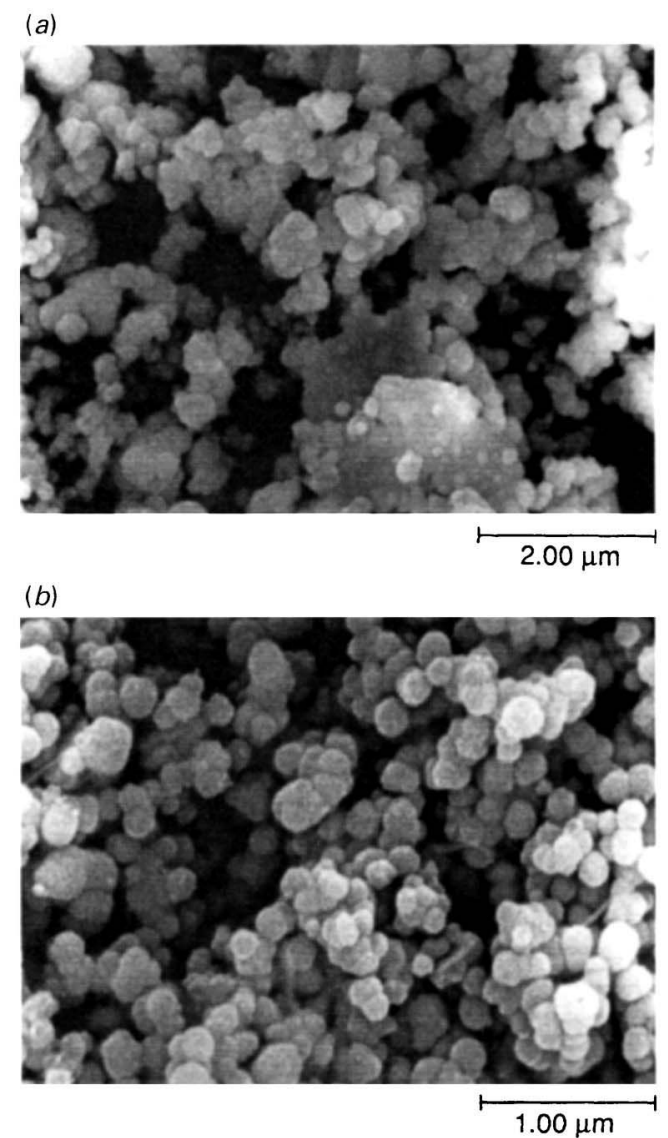

Fig. 7 SEM images of $\mathrm{ZnS}$ prepared at $100^{\circ} \mathrm{C}$ for $30 \mathrm{~min}$ from solutions containing thioacetamide and (a) ethylenediamine or (b) triethanolamine

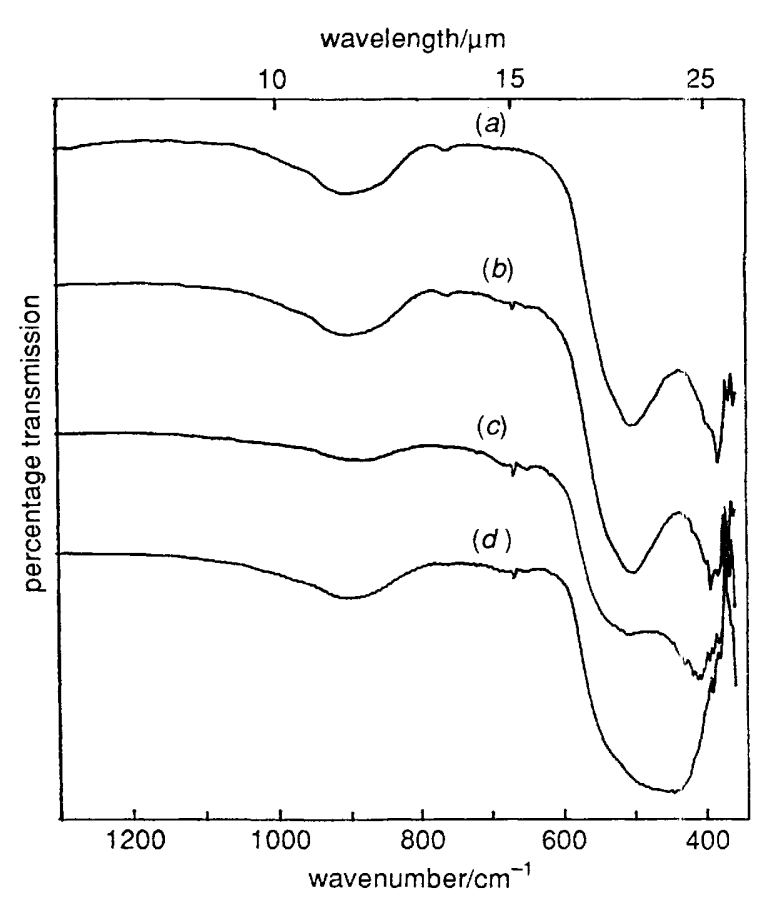

Fig. 8 FTIR spectra of the $\mathrm{ZnO}$ samples: (a) sample A, (b) sample B, $(c)$ sample $\mathrm{C}$ and $(d)$ sample $\mathrm{D}$ in $\mathrm{KBr}$ pellets

Some published work on the preparation of well defined particles in the presence of organic ligands has used equilibrium arguments ${ }^{23}$ while in other cases the chemical degradation of the organic ligand has been involved. ${ }^{11}$ In an attempt to clarify the fate of the ligand for the present systems en was quantitatively determined in the solutions from which $\mathrm{ZnO}$ precipitation had occurred. The results of these experiments showed that the en does not decompose.

An effort was made to determine if parameters such as $\mathrm{pH}$, the anion, the reaction time, the temperature and the ionic strength affected the $\mathrm{ZnO}$ powders. The experimental parameters summarized in Table 2 were studied and the results showed no evidence for a pronounced effect of these variables on the characteristics of the $\mathrm{ZnO}$ particles, in contrast to the ligand or the nature of the hydrothermal treatment. In two cases slight effects were noticed. Slightly different $Z . \mathrm{nO}$ particles were obtained in the presence of en and sulfate ions [Fig. 5(a)]. This could be related to the complexing effect of this anion, which is more pronounced than for the other anions studied in this work. In one experiment at an ionic strength of $1.06 \mathrm{~mol} \mathrm{~kg}^{-1}$, in the presence of en, the $\mathrm{ZnO}$ particles were deaggregated [Fig. 5(b)].

The $\mathrm{ZnS}$ obtained from the alkaline medium was of poorly defined morphology and at the highest $\mathrm{pH}$ value used $(\mathrm{pH} 13.0)$ a gelatinous precipitate was obtained. However, when thermal treatment at $60^{\circ} \mathrm{C}$ was performed on solutions at $\mathrm{pH} 6.0$, nearly spherical submicrometre particles were obtained for both en and tea ligands (Fig. 6). The effect of the ligand on the shape of the $\mathrm{ZnS}$ particles was not as marked as the results for the $\mathrm{ZnO}$ powders. The SEM results for $\mathrm{ZnS}$ suggest that the best defined and most uniform morphologies are obtained in the presence of tea. Agglomeration is marked in both cases. The fact that the experiments were performed at $\mathrm{pH} 6.0$ means that both en and tea will be partially protonated; however, the ionization of the ligand is promoted by coordination and marked effects upon particulate formation are observed. When the temperature of the solutions is increased the agglomeration of the $\mathrm{ZnS}$ particles is promoted and their size is greater for similar 
Table 5 Published ${ }^{27}$ stability constants $\left(25^{\circ} \mathrm{C}\right.$ and $\left.I=0.1 \mathrm{~mol} \mathrm{~kg}^{-1}\right)$ for complexes of zinc and the ligands used in this work

\begin{tabular}{|c|c|c|}
\hline ligand & equilibrium & $\log K$ \\
\hline \multirow[t]{2}{*}{ mea } & ML/M.L & $2.70^{a}$ \\
\hline & $\mathrm{ML}_{2} / \mathrm{M} \cdot \mathrm{L}^{2}$ & $4.78^{a}$ \\
\hline \multirow[t]{2}{*}{ tea } & $\mathrm{ML} / \mathrm{M} . \mathrm{L}$ & 2.05 \\
\hline & $\mathrm{ML}_{2} / \mathrm{M} \cdot \mathrm{L}^{2}$ & 3.28 \\
\hline \multirow[t]{4}{*}{ ammonia } & ML/M.L & $2.21^{b}$ \\
\hline & $\mathrm{ML}_{2} / \mathrm{M} \cdot \mathrm{L}^{2}$ & $4.50^{b}$ \\
\hline & $\mathrm{ML}_{3} / \mathrm{M} \mathrm{L}^{3}$ & $6.86^{b}$ \\
\hline & $\mathrm{ML}_{4} / \mathrm{M} \cdot \mathrm{L}^{4}$ & $8.89^{b}$ \\
\hline \multirow[t]{5}{*}{ diethylamine } & ML/M.L & 2.97 \\
\hline & $\mathrm{ML}_{2} / \mathrm{ML} . \mathrm{L}$ & 2.60 \\
\hline & $\mathrm{ML}_{3} / \mathrm{ML}_{2} \cdot \mathrm{L}$ & 2.34 \\
\hline & $\mathrm{ML}_{4} / \mathrm{ML}_{3} \cdot \mathrm{L}$ & 1.92 \\
\hline & $\mathrm{ML}_{\mathbf{4}} / \mathrm{M} \cdot \mathrm{L}^{4}$ & 9.83 \\
\hline \multirow[t]{3}{*}{ en } & $\mathrm{ML} / \mathrm{M} . \mathrm{L}$ & 5.7 \\
\hline & $\mathrm{ML}_{2} / \mathrm{M} \cdot \mathrm{L}^{2}$ & 10.6 \\
\hline & $\mathrm{ML}_{3} / \mathrm{M} \cdot \mathrm{L}^{3}$ & 12.6 \\
\hline \multirow[t]{2}{*}{ dien } & ML/M.L & 8.8 \\
\hline & $\mathrm{ML}_{2} / \mathrm{M} \cdot \mathrm{L}^{2}$ & 14.5 \\
\hline trien & $\mathrm{ML} / \mathrm{M} . \mathrm{L}$ & 12.0 \\
\hline EDTA & ML/M.L & 16.5 \\
\hline \multirow{2}{*}{ NTA } & $\mathrm{ML} / \mathrm{M} . \mathrm{L}$ & 10.7 \\
\hline & $\mathrm{ML}_{2} / \mathrm{M} \cdot \mathrm{L}^{2}$ & 14.2 \\
\hline \multirow[t]{5}{*}{$\mathrm{OH}^{-}$} & $\mathrm{ML} / \mathrm{M} . \mathrm{L}$ & $5.0^{b}$ \\
\hline & $\mathrm{ML}_{2} / \mathrm{M} \cdot \mathrm{L}^{2}$ & $11.1^{b}$ \\
\hline & $\mathrm{ML}_{3} / \mathrm{M} \mathrm{L}^{3}$ & $13.6^{b}$ \\
\hline & $\mathrm{ML}_{4} / \mathrm{M} \cdot \mathrm{L}^{4}$ & $14.8^{b}$ \\
\hline & $\mathrm{M}_{2} \mathrm{~L} / \mathrm{M}^{2} \cdot \mathrm{L}$ & $5.0^{b}$ \\
\hline
\end{tabular}

${ }^{a} I=0.5 \mathrm{~mol} \mathrm{~kg}^{-1} \cdot{ }^{b} I=0 \mathrm{~mol} \mathrm{~kg}{ }^{-1}$.

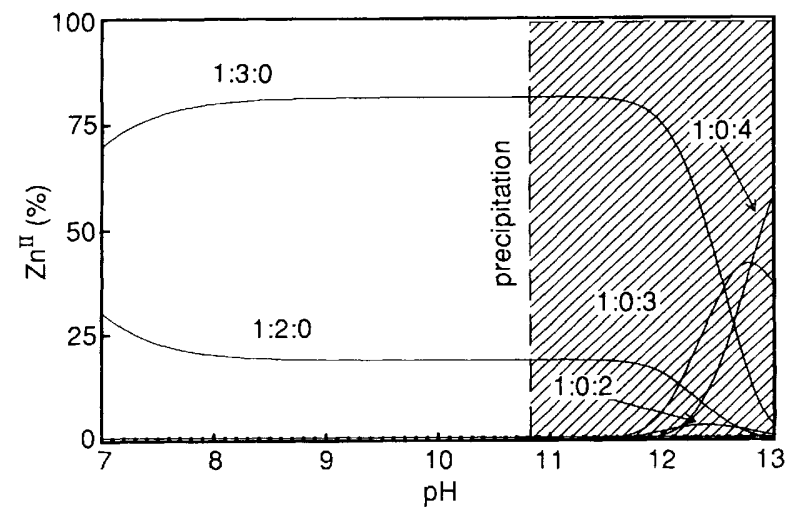

Fig. 9 Speciation diagrams of the zinc-ethylenediamine system at room temperature $\left(25^{\circ} \mathrm{C}\right)$, using the values of Table 5 , for the system $\left[\mathrm{Zn}^{2+}\right]:[\mathrm{en}]=1: 5,\left[\mathrm{Zn}^{2+}\right]=0.02 \mathrm{~mol} \mathrm{l}^{-1}$. Species as $\mathrm{M}_{a}(\mathrm{en})_{b}(\mathrm{OH})_{\mathrm{c}}$.

aging times. Fig. 7 shows such effects for particles obtained at $100^{\circ} \mathrm{C}$

\section{Use of FTIR Absorption Spectra in Powder Characterization}

The morphological characteristics of small particles can, for ionic oxides of well defined shape, have a marked effect on the IR spectrum due to dipole oscillations induced by the vibrational modes. Applying a generalized theory of the dielectrics, Hayashi et al. successfully interpreted the experimental IR spectra ${ }^{24}$ of zinc oxide. A theoretical IR spectrum for particles with a defined shape and state of agglomeration can be derived by adjusting a shape factor, $g$, and a filling factor, $f$. The influence of the shape and agglomeration state of the $\mathrm{ZnO}$ particles on the transverse optical modes, $W_{\mathrm{T} \perp}=377 \mathrm{~cm}^{-1}$ and $W_{\mathrm{T} \|}=406 \mathrm{~cm}^{-1}$, can be studied.

The $\mathrm{ZnO}$ particles described in this work present sufficiently specific morphologies for an attempt to correlate shape and spectra. ${ }^{24-26}$ Even though the preparation of the $\mathrm{KBr}$ pellets must lead to some changes in the particles, sufficient morphological differences remain for distinct spectra to be observed for different samples (Fig. 3). The FTIR spectra of some of the $\mathrm{ZnO}$ powders are shown in Fig. 8. The spectra are characteristic of zinc oxide and no organic or carbonate residues were detected in the spectra. However, some differences in the band profiles can be seen for the different $\mathrm{ZnO}$ samples.

Sample D consists of small nodular particles in which aggregation is facilitated, and a single band at $443 \mathrm{~cm}^{-1}$ is observed. The samples A, B and C have preferential growth along the $c$ axis, and show splitting of the absorption band. These results agree well with those reported by others. ${ }^{24,26}$

\section{Conclusions}

The results of this study suggest that the organic ligand not only inhibits $\mathrm{Zn}(\mathrm{OH})_{2}$ precipitation, allowing a controlled synthesis of $\mathrm{ZnO}$, but can also play a specific role in controlling the growth of the particles under different orientations. The morphological characteristics of the $\mathrm{ZnO}$ particles depend both on the presence of organic ligands and their chemical nature.

LaMer and Dinegar ${ }^{15}$ claimed that the morphology of colloidal particles is controlled by the speciation of the solution present during the nucleation and growth of the particulate materials, and this idea appears to be confirmed by our observations. The lack of thermodynamic and kinetic data for these systems under the conditions used does not allow a thorough discussion of this hypothesis. However, the stability constants available ${ }^{27}$ (Table 5), although determined for other conditions, show that the solution speciation should be quite different for the range of ligands used. A simple calculation (carried out with the program SPECIES, Dr. L.D. Pettit, University of Leeds) suggests that the zinc:en system $(1: 5)$ at room temperature is unstable with respect to the precipitation of the hydroxide at $\mathrm{pH} 10.85$ whereas the zinc-tea $(1: 5)$ system becomes unstable at $c a$. pH 7.0 (Fig. 9). Undoubtedly both thermodynamic and kinetic factors are important in the control of the precipitation mechanism of $\mathrm{ZnO}$ and $\mathrm{ZnS}$ particulates. SEM results show clearly that the organic ligands strongly influence the powder properties of both materials when they are obtained from solutions where they are present.

This work was financed by Junta Nacional de Investigacao Científica e Tecnológica (Portugal).

\section{References}

1 G. W. Kriechbaum and P. Kleinschmith, Adv. Mater., 1989, 61, 1416.

2 M. L. Levinson and H. R. Philipp, J. Appl. Phys., 1975, 46, 1332.

3 F. A. Selim, T. K. Gupta, P. L. Hower and W. G. Carlson, J. Appl. Phys., 190, 51, 765 .

4 R. J. Lauf and W. D. Bond, Bull. Am. Ceram. Soc., 1984, 63, 278.

5 M. A. Alim, M. A. Seitz and R. W. Hirthe, J. Am. Ceram. Soc., 1988,71, C-52.

6 Dictionary of Inorganic Compounds, ed. J. E. Macintyre, Chapman and Hall, London, 1992, vol. 3, p. 3797.

7 D. Segal, in Chemical Synthesis of Advanced Ceramic Materials, ed. A. R. West and E. H. Baxter, Cambridge Lniversity Press, Cambridge, 1989.

8 E. Matijevic, Annu. Rev. Mater. Sci., 1985, 15, 483.

9 Biomineralization, ed. S. Mann, J. Webb and R. J. P. Williams, VCH, Weinheim, 1989.

10 R. S. Sapieszko and E. Matijevic, J. Colloid Interface Sci., 1980, 74, 405 .

11 R. S. Sapieszko and E. Matijevic, Corrosion, 1980, 36, 522.

12 H. Nishizawa, T. Tani and K. Matsuoka, J. Am. Ceram. Soc., 1984, 67, C-98. 
13 T. Liu, O. Sakurai, N. Mizutani and M. Kato, J. Mater. Sci., 1986 67, 3698 .

14 D. M. Wilhelmy and E. Matijevic, J. Chem. Soc., Faraday Trans. $1,1984, \mathbf{8 0}, 563$.

15 V. K. LaMer and R. H. Dinegar, J. Am. Chem. Soc., 1950, 72, 4847.

16 G. Hihara, H. Miyamae and M. Nagata, Bull. Chem. Soc. Jpn., $1981, \mathbf{5 4}, 2668$

17 T. S. Trindade, A. M. V. Cavaleiro, J. D. Pedrosa de Jesus and J. L. Baptista, Actas do XI Encontro da Sociedade Portuguesa de Química, 1988, 2, 705.

18 A. Chittofrati and E. Matijevic, Colloids Surf., 1990, 48, 65.

19 M. Castellano and E. Matijevic, Chem. Mater., 1989, 1, 78.

20 T. P. Dirkse, in IUPAC Solubility Data Series, 23, Pergamon Press, Oxford, 1986, p. 156.

21 Powder Diffraction File: Inorganic Phases, JCPDS, International Centre for Diffraction Data, USA, 1989.
22 T. P. Dirkse, C. Postmus Jr. and R. Vandenbosch, J. Am. Chem. Soc., 1954, 76, 6022 .

23 M. J. Kim and E. Matijevic, Chem. Mater., 1989, 1, 363.

24 S. Hayashi, N. Nakamori and H. Kanamori, J. Phys. Soc. Jpn., $1979,46,17$.

25 K. Yamamoto, C. Tran, H. Shimizu and K. Abe, J. Phys. Soc. Jpn., $1979, \mathbf{4 2}, 587$.

26 M. Andrés-Vergés and M. Martinez-Gallego, J. Mater. Sci., 1992, 27, 3756.

27 R. M. Smith and A. E. Martell, Critical Stability Constants, Plenum Press, New York, vol. 2, 1975; 1976 vol. 4. 19\&2, vol. 5, 1989, vol. 6; D. D. Perrin, Stability Constants of Metal Ion Complexes, Part B: Organic Ligands-IUPAC Chemical Data Series 22, Pergamon Press, Oxford, 1979.

Paper 3/04719I; Received 5th August, 1993 